\title{
La retención de las tierras de indios en el México colonial: una revisión historiográfica
}

VÍCTOR M. GONZÁLEZ ESPARZA

Departamento de Historia/UAA

1

NTRODUCCIÓN

La discusión sobre las tierras de indios en el México colonial tiene su origen desde el momento mismo del descubrimiento. La polémica sobre las nuevas tierras a través del "regalismo", involucró desde luego a los antiguos propietarios planteando algunas preguntas sobre los derechos de la conquista. ¿Las nuevas tierras pertenecían a la corona $o$ a las antiguas jerarquías indígenas? En todo caso, ¿cómo se realizó el proceso de transposición del concepto de propiedad y de jurisdicción prehispánica al del derecho indiano? ¿Qué elementos contribuyeron a la preservación de las tierras de indios, pese a la conquista y la colonización? Existe la tendencia entre los estudiosos a no considerar estas preguntas, dado que se parte del supuesto, propio de la época moderna, de que las formas de propiedad españolas acabaron por predominar, no obstante los constante indicios aún vigentes que nos hablan de un proceso complejo de largo plazo en el que las tierras (y otros derechos) de los indios continúan siendo más que un tema de debate.

El presente trabajo, sin embargo, pretende dar cuenta de una discusión historiográfica contemporánea, surgida fundamentalmente a partir de los años setenta, en donde las haciendas dejan de ser el sujeto fundamental de análisis y las tierras y comunidades de 
indios adquieren mayor relevancia, en función de la pregunta sobre los factores que contribuyeron básicamente en la época colonial a que un número significativo de pueblos de indios retuvieran sus tierras. Ciertamente, una pregunta previa se encuentra en las formas prehispánicas de propiedad y sus transformaciones al momento de la conquista, lo cual requiere de mayores estudios.*

Los estudios contemporáneos sobre la retención de las tierras por las comunidades indígenas se encuentran lógicamente vinculados a la historiografía sobre la hacienda mexicana, en especial a partir de la obra de François Chevalier. Sin embargo, el "paradigma" que Chevalier consolidó tiene sus orígenes, como sabemos, en los trabajos de Wistano Luis Orozco y, particularmente, de Andrés Molina Enríquez. ${ }^{1}$ Me parece importante por ello referir brevemente las opiniones de algunos estudiosos anteriores a Chevalier, con el fin de contextualizar en un primer momento las aportaciones de éste, para luego pasar a la crítica de este paradigma desde la retención de las tierras de indios.

\footnotetext{
* Sobre este aspecto existe un excelente ensayo de Bernardo García Martínez "Jurisdicción y propiedad: Una distinción fundamental en la historia de los pueblos de indios del México Colonial", en Revista Europea de Estudios Latinoamericanos y del Caribe, Número 53, Diciembre de 1992, pp.47-60. El autor realiza una distinción importante existente en el sistema prehispánico entre propiedad propiamente y jurisdicción, en donde esta última tenía que ver más con las bases de asociación política que estrictamente territorial.

1. Este sociólogo y jurista mexicano, autor de la obra clásica Los grandes problemas nacionales (1909), recuperando una tradición crítica al menos desde Jovellanos, explicó precisamente los grandes problemas nacionales de principios de este siglo a partir de la escasez de alimentos básicos para la población. Pero, ¿qué provocaba dicha escasez? El acaparamiento, respondió Molina Enríquez, por parte de los grandes latifundios sobre las pequeñas propiedades (privadas y comunales), principales productoras de alimentos en el país. Molina Enríquez sabía de lo que hablaba, pues su actividad profesional como abogado había culminado en una Notaría en el Valle Central mexicano. Sin embargo, su argumento encajó perfectamente en la ideología revolucionaria logrando de esta manera sobrepasar los límites explicativos que el propio Molina Enríquez imaginara. V. Andrés Molina Enríquez, Los grandes problemas nacionales. México, A. Carranza e hijos, 1909.
} 
Algunos autores norteamericanos también contribuyeron a alimentar el modelo explicativo predominante sobre el campo novohispano, en el que las tierras de indios son devoradas por las haciendas. Habría que citar por lo menos a McBride, Tannenbaum, Simpson, todos autores de excelentes trabajos por la cercanía y calidad con la que explicaron las raíces agrarias de la revolución mexicana. Sin embargo, todos fueron partícipes del mismo argumento.

Cito a McBride:

El pueblo pudo ser visto como un rival de la hacienda y, en menor sentido, del rancho. En la lucha por la supremacía la hacienda y el rancho generalmente han ganado. Ha existido una tendencia constante a absorber a los pueblos por las haciendas... ${ }^{2}$

Frank Tannenbaum por su parte enunció claramente el debate que años más tarde se llevaría a cabo, planteando incluso parte de las dudas historiográficas recientes:

El pueblo libre existe, pero su vida económica está dominada por la hacienda. Esto es de una manera general, aunque debe recordarse siempre que algunos grupos indígenas, como los que hemos designado con el nombre de "comunidades dispersas", se hallan fuera del dominio de las grandes propiedades, y también que cierto número de congregaciones tienen abundancia de tierra para sus necesidades, más de las que utilizan o pueden utilizar. Sin embargo, estos grupos son una minoría. ${ }^{3}$

Finalmente, otro de los clásicos que vale la pena, pese a todo, conocer, Eyler N. Simpson:

2. George McCutchen McBride The Land System of Mexico. With a Foreward by Manuel Gamio. New York, American Geographical Society, 1923, 204 pp. La cita en la p. 126.

3. Frank Tannenbaum "La Revolución Agraria Mexicana" (c.1929) en Problemas Agrícolas e Industriales de México, Núm. 2, Vol. IV, 1952. Cita en p. 33. 
la historia de México es, en sus aspectos más fundamentales, el drama de la lucha entre el feudalismo y el pueblo libre, entre la propiedad privada individual y la propiedad comunal, colectiva; en resumen, entre la hacienda y el ejido. Por espacio de 400 años es la hacienda la que gana; las victorias de los pueblos son sólo triunfos temporales... ${ }^{4}$

De acuerdo a las versiones anteriores, el estudio de la hacienda más que el de las comunidades indígenas aparecía como un elemento fundamental para entender la historia rural de México. Precisamente el debate historiográfico que a continuación voy a reseñar se explica por la escasez de estudios sobre la historia de los indios frente a una sobredimensión de los análisis sobre las haciendas. Sin embargo, el debate se acentuó en el momento (a partir de los años setentas) en que se iniciaba una revisión general de la historia mexicana. Frente a la visión de los vencedores, se pensaba, había que darle voz a los vencidos. Por otra parte, nuevas fuentes y nuevas metodologías (como la etnohistoria) se ensayaban.

Pero antes de reseñar estos debates, el presente trabajo comienza con una breve reseña de lo que se ha dado en llamar "historia institucional", es decir, una historia rural enfocada a través de las instituciones y del derecho indiano. De manera sobresaliente en esta perspectiva están Ots Capdequí, Silvio Zavala y José Miranda, los cuales serán comentados.

En segundo lugar, me concentro en el "modelo Chevalier-Borah" en donde las haciendas son el referente principal, comentando las aportaciones de Charles Gibson dentro de este mismo apartado, por ser éste, el maestro de los historiadores que plantearían el debate posterior con base en la etnohistoria. En tercer lugar sintetizo las críticas al "modelo Chevalier-Borah" a partir de los trabajos de William B. Taylor y Wayne Osborne, pasando por las consideraciones de estudiosos como Nancy Farris, Spores, etc. Concluyo con

4. Eyler N. Simpson "El Ejido: Única salida para México" en Problemas Agrícolas e Industriales de México, Vol. IV: 4, 1952, p. 21. 
breves comentarios a esta polémica historiográfica. Adelanto mi parecer: más que un nuevo modelo o paradigma, la polémica reafirmó las excepciones que confirman la regla, es decir, aclaró las variantes del modelo. Sin embargo, en el debate mismo se brindó la oportunidad de ensayar nuevas metodologías y descubrir nuevas fuentes.

Ciertamente el estudio de las etnias y sus recursos se encuentra entre "los olvidos de Clío." No obstante ello, el tema de la preservación de las tierras de indios permite adentrarse en la historia rural mexicana desde una perspectiva más amplia. Por ejemplo, el proceso de "privatización" o de "individualización" de la propiedad, proceso que es consustancial al desarrollo del capitalismo, permite observar por ejemplo que las tierras comunales indígenas no se redujeron sólo por el acaparamiento de las haciendas sino que también la privatización ocurrió al interior mismo de las comunidades, sobre todo a partir del siglo XviII. Ello significa que si bien podemos encontrar variantes al modelo original (ChevalierBorah), también es necesario profundizar en el estudio de los elementos históricos fundamentales al interior de las propias comunidades con el fin de entender en su complejidad la historia rural y cultural del país.

\section{LA VISIÓN INSTITUCIONAL}

Más allá de la polémica sobre si los indios eran verdaderos propietarios o si por el contrario las tierras eran realengas, es ya un lugar común el reconocer el interés de los legisladores españoles, desde los primeros momentos del descubrimiento, por imponer una política orientada a que el indio no se desvinculase de la tierra. En una de las obras pioneras sobre El Régimen de la Tierra en la América Española durante el Periodo Colonial José Ma. Ots Capdequí señaló que en todas las capitulaciones, "absolutamente en todas", se hace constar que los repartimientos de tierras se harían sin agra- 
vios a los indios. Al igual que en las Ordenanzas de Felipe II (1573), en la obra de Matienzo (Gobierno de Perú), en la de Solórzano y Pereyra, y en la Recopilación se asienta: "que a los indios se les dexen tierras..." ${ }^{5}$

En el momento en que Ots Capdequí escribió no había dudas para explicar el porqué de esta política proteccionista:

Fácilmente se comprende que el Estado español (...) desde el punto de vista económico y desde el punto de vista fiscal, tenía interés en que el indio fuese un sujeto de capacidad tributaria; por eso los grandes tratadistas del derecho indiano dedican a este tema atención especial.

Sin embargo, el problema histórico se encontraba en otra parte como bien lo señalara Ots Capdequí. Cito nuevamente:

el divorcio entre el hecho y el derecho no se produce en ningún otro aspecto de la obra colonizadora desarrollada por España en América con tanta intensidad como en éste que se refiere al problema del indio, en todos sus aspectos y concretamente del indio en relación con la tierra. ${ }^{6}$

Menciona incluso investigaciones en que se comenzaba a mostrar no sólo la "codicia insaciable del colonizador", sino también cómo el interés del Estado se veía burlado por la ambición de los conquistadores.

Ots Capdequí finalizó el capítulo de las tierras de indios con una duda sobre si tales tierras sobrevivieron dentro de las encomiendas. Precisamente sobre este tema, corroborando los intereses incluso de los encomenderos por proteger las tierras indígenas, Silvio Zavala publicó un ensayo titulado "De encomiendas y propiedad territorial en algunas regiones de la América española" (1940), en el cual afirmó: "Lã defensa de la propiedad de los indios coincidía

5. José Ma. Ots Capdequí, El Régimen de la Tierra en la América Española durante el Periodo Colonial, Universidad de Sto. Domingo, 1946, pp. 98-104.

6. Ibid.pp. 100, 103. 
entonces (mediados del siglo XVI) con el interés de los encomenderos, y éste, de buen grado, reconocía el derecho de propiedad indígena enfrentado a las ambiciones de los terceros ("intrusos") españoles". ${ }^{7}$ El problema se complicaba cuando los intereses de los encomenderos entraban en conflicto con los derechos indígenas. Así, no obstante que el derecho indiano mejoró la protección en relación al derecho medieval de los labradores, en la práctica las diferencias culturales perjudicaron a los indígenas, como lo ejemplificó el mismo Silvio Zavala básicamente para el Marquesado del Valle. Comentó también que a las tierras pertenecientes a la nobleza indígena prehispánica no se les asignó una protección urgente como a las de las comunidades; sin embargo, la situación de los caciques "solía ser mejor", ya que tenían derecho a tierras en propiedad individual y a repartimiento de indios. ${ }^{8}$ Es interesante hacer notar que para Silvio Zavala la retención de tierras por indígenas no era un problema en sí mismo, ya que se explicaba fácilmente por la necesidad misma de los pocos españoles en tener fuentes de alimento y de tributo, así como mano de obra indígena. Posteriormente el mismo Silvio Zavala le dedicaría buena parte de sus esfuerzos como historiador a descubrir las fuentes documentales del trabajo indígena, contribuyendo con ello a la nueva historia de los indios.

Dentro de esta misma perspectiva institucional debe incluirse al historiador José Miranda, quien fue de los primeros en publicar un artículo explícitamente consagrado a explicar las causas y los motivos de la retención de la tierra por los indios: "La propiedad comunal de la tierra y la cohesión social de los pueblos indígenas mexicanos". ${ }^{9}$ Miranda señaló claramente la estrecha relación entre

7. Silvio Zavala, Estudios Indianos, El Colegio Nacional, 1948, pp. 205-307. La cita en p. 258.

8. Ibid. pp. 287, 297.

9. José Miranda, Vida Colonial y albores de la Independencia, México, SEP-SETENTAS, 1972, pp. 54-79. El artículo apareció originalmente en Cuadernos Americanos, 1966. 
tierra y cohesión indígena desde la época prehispánica. Pese a que en la época colonial esta relación se vió seriamente afectada, hubo elementos que actuaron claramente a favor de las tierras indígenas. Los argumentos principales de Miranda al respecto fueron: 1) el rechazo al estilo de vida español y, por lo tanto, la reafirmación de los propios principios indígenas; 2 ) la relativa separación formal y espacial de indios y españoles; 3) la importancia que le concedieron los mismos españoles a las tierras indígenas, especialmente como fuente de alimentos y de tributos; 4) la conservación por los indios de una relativa autonomía municipal y política, lo cual mantuvo vivos muchos valores, normas y prácticas, y 5) el poco número de españoles en algunas regiones.

En ellas (en las regiones con más tierras indígenas), tuvo por fuerza que ser mucho menor que en otras la presión ejercida sobre las tierras indígenas por los hispanos. Así ocurrió en Oaxaca, donde, al final de la época colonial, los españoles constituían apenas el $6.5 \%$ de la población, y en Puebla, donde sólo llegaban al $12 \% .^{10}$

Así pues, refiere Miranda, el juego de los distintos factores favorables y adversos (entre estos últimos el intento de "civilizar" a los indios y la diferente concepción de la propiedad entre los españoles) actuando en diferentes regiones, resultó variado en consecuencia para la supervivencia de la propiedad comunal.

Además de los anteriores factores generales, Miranda describió algunos de los medios legales por los cuales las comunidades consolidaron e incluso ampliaron sus propiedades: a) resguardos especiales otorgados por los virreyes para las tierras amenazadas ("de seguro y amparo"); b) obtención vía la merced de terrenos baldíos cercanos; c) obtención de la reserva de tierras comarcanas; d) solicitud de amparos virreinales para evitar las ventas ilegales o cortar las presiones sobre la tierra. Junto con los anteriores, se dieron

10. Ibid., p. 59. 
también otros de carácter pacífico aunque no legales, como la prolongación ficticia de las sementeras y poblados para crear un colchón entre sus tierras y las de los españoles. Pero definitivamente los más temibles fueron los de índole violenta: quema de campos y cultivos, matanza de ganados y, de vez en vez, ataques a las haciendas y levantamientos armados.

Dentro de todos los anteriores elementos considerados, en opinión de Miranda lo que más contribuyó a la cohesión social y, por lo tanto, a la retención de las tierras indígenas fue otra preservación, la del régimen y gobierno de las comunidades. "Fue aquella aristocracia, concluye Miranda, la antigua y la nueva o la mezcla de ambas, la que supo conservar el depósito de tradiciones y costumbres, y mantener vivo el espíritu propio frente al ajeno..."

Como veremos más adelante, Miranda anticipó muchas de las respuestas al problema planteado por la sobrevivencia de tierras comunales. Una más. Como sabemos, a final del periodo colonial la presión sobre las tierras comunales se incrementó considerablemente. La "privatización" se explica entonces por las condiciones generales de miseria de los pueblos de indios, así como por su incapacidad de crecer dado el aumento de la población y el "cercamiento" de las propiedades españoles sobre las indígenas. Este tipo de explicación, por cierto, poco ha sido explorada.

Se ha convertido en un lugar común el rechazar sin leer a los autores ubicados en la perspectiva institucional. Sin embargo, como resulta de los autores aquí reseñados, puede decirse que no sólo atendieron los problemas de la retención de las tierras de indios sino que también anticiparon algunas respuestas al actual debate historiográfico.

11. Ibid., p. 65. 


\section{El "Modelo ChevalieR"}

La obra de François Chevalier desde el momento mismo de su aparición fue señalada como un clásico. ${ }^{12}$ Lesley Byrd Simpson, por ejemplo, quien acababa de publicar su libro sobre La explotación de la tierra en el México central en el siglo XVI (Berkeley, 1952), comentó: "Chevalier ha escrito un estudio y no sólo una monografía". ${ }^{13}$ La obra de Chevalier causó impacto porque nos dijo todo lo que queríamos saber sobre las haciendas y no nos atrevíamos a investigarlo. Por ello no extraña que el mismo Simpson haya comentado que "hay poco asombroso o inesperado en este estudio." ¿Por qué entonces el interés en la obra de Chevalier? Simpson también responde: porque es una obra desafiante e inspiradora. ${ }^{14}$

En iguales términos se refirió Lucien Febvre, el gran maestro de la "escuela francesa," sobre la obra de Chevalier: "Ese es precisamente el gran interés de este estudio; que solicita; que compromete... que plantea preguntas; que nos pone sobre la pista de respuestas útiles" ${ }^{15}$ Para Pierre Chaunnu la originalidad del libro de Chevalier se encuentra en la manera en que el autor muestra cómo la nueva clase dirigente, "los señores de la tierra", se van apropiando de la tierra de los antiguos mexicanos, eliminando el divorcio hasta

12. François Chevalier, La formation des grandes domains au Mexique. Terre et Société aux XI'I-XIII Siécles. Paris, Institut D'Ethnologie, 1952, 480 pp. La primera versión en español apareció en Problemas Agrícolas e Industriales de México, Vol. VIII:1, 1956, 291 pp. La primera en inglés en 1966 por Berkeley con prólogo de Lesley Byrd Simpson. Las primeras versiones en inglés y en español aparecieron abreviadas. La segunda edición en español, corregida y aumentada, apareció hasta 1979 en Fondo de Cultura Económica.

13. En Hispanic American Historical Review, February 1952, reproducida en la primera versión de Problemas Agrícolas e Industriales de México, Op. cit., "Nuevas luces en la historia del latifundismo mexicano", pp. 283-285.

14. Ibidem.

15. Lucien Febvre, "Les grans domaines au Mexique", Annales, Economies, Societés, Civilisation, 1953, reproducido en Problemas Agrícolas e Industriales de México, Op. cit., pp. 282-283. 
entonces existente entre el derecho y su práctica en el estudio de las nuevas tierras en la historiografía institucional. Por otra parte, de acuerdo con Chaunnu, le debemos a Chevalier el haber demostrado la existencia de dos Méxicos

extremadamente diferentes, por no decir antitéticos: un México húmedo, al Sur; un México seco, al Norte. El primero se relaciona con la civilización de las altiplanicies (...) Como las altas mesetas del Perú, a las cuales se parece, soportaba a la llegada de los españoles una población densa (...) Este es, aún hoy, el México indígena, o por lo menos el México donde más abunda la raza obscura: es allí donde la propiedad colectiva india ha resistido mejor, o menos mal, la invasión de las grandes propiedades. ${ }^{16}$

Ciertamente el objetivo de Chevalier fue la hacienda española y no las comunidades indígenas. En cierta forma su visión sobre estas últimas continuó siendo institucional: un repaso rápido sobre las formas prehispánicas de propiedad para concluir con el análisis de la sustitución de la nobleza indígena por los conquistadores, particularmente en el Valle Central, lo cual favoreció el desarrollo de las haciendas pese a la protección legal del indio y del régimen tutelar de las misiones. ${ }^{17}$

Chevalier era consciente de sus límites y, a mi modo de ver, planteó una pregunta aún difícil de responder:

Finalmente, en toda la Nueva España y en las provincias del Norte, ¿cuál fue la proporción de los pueblos y caseríos invadidos por los colonos e incorporados a las haciendas, de las comunidades reducidas a sus 600 varas legales, y de las que, por el contrario, pudieron conservar tierras suficientes y aún propiedades de importancia? Es imposible contestar esta pregunta mientras gran número de monografías locales y regionales no vengan a colmar las lagunas actuales, mientras no se haya investigado la situación

16. Pierre Chaunu, "Un gran paso en la historiografía americanista", en Problemas Agrícolas... Op. cit., pp. 280-281, publicado originalmente en Revue Historique, julio-septiembre, 1950. En realidad es un comentario a la tesis de Chevalier, la cual fue presentada en 1949 en la Sorbona para obtener el Doctorado en Letras.

17. Chevalier, Op. cit., 2a ed. en español, pp. 37-48, 234-272. 
reinante en el siglo XVIII, y no se hayan estudiado las enajenaciones de tierras comunales a raíz de la ley de $1856 .{ }^{18}$

Simpson es nuevamente claro al respecto: no desarrolló análisis cuantitativos, ni los efectos del sistema de propiedad sobre el pueblo que hacía la tarea, ni los cambios sociales ocurridos por la industrialización del azúcar y de la lana, etc. Sin embargo, concluyó Simpson, Chevalier ha escrito "lo que quería escribir y no lo que el cronista quisiera que hubiera escrito. En su defensa puede decirse que la exploración apropiada de estos tópicos le hubiera llevado años de trabajo y algunos volúmenes más. Hizo bien, por lo tanto, en limitarse a la evolución de la hacienda..."

Ahora bien, el modelo Chevalier fue tardíamente cuestionado, quizá más certeramente en la relación de la hacienda con el mercado y la economía en general que en relación con las comunidades indígenas. ${ }^{20}$ La perspectiva sobre la herencia medieval, la cual Chevalier adopta para estudiar las haciendas, también ha sido revisada. Es explícita la influencia de Marc Bloch; sin embargo, tal y como lo vio el propio Bloch para la historia rural francesa, la tendencia a la "individualización" de la propiedad es lo que predomina para el mundo moderno. En esta última perspectiva es contradictoria la visión de Chevalier: herencia medieval, semifeudal, de los latifundios por una parte, absorción privada de las propiedades comunales por la otra. Contradicción que llevaría a Chevalier a

18. Ibid., p. 271

19. Simpson, "Nuevas luces..." en Problemas Agrícolas... Op. cit.

20. Para una revisión amplia sobre el modelo Chevalier y la historiografía de la hacienda colonial, es indispensable consultar a Eric Van Young "La historia rural de México desde Chevalier: historiografía de la hacienda colonial", Historias 12, 1986, pp. 23-65. Sobre las preguntas generales planteadas por Chevalier y Simpson en relación a la transformación cuantitativa de las comunidades rurales, son fundamentales los trabajos de Peter Gerhard, en "La evolución del pueblo rural mexicano: 1519-1975”. En Historia Mexicana, Vol. XXIV: 4, 1975, ofrece una síntesis muy sugerente. 
subestimar una tendencia más amplia de privatización de las propiedades comunales, al introducir la herencia medieval en la formación de la hacienda.

El mismo año en que se publicó en Francia el libro de Chevalier, Charles Gibson sacó a luz su primera gran obra: Tlaxcala in the Sixteenth Century. ${ }^{21}$ A diferencia del libro de Chevalier, esta pequeña gran obra comenzó a ser reconocida tardíamente. A diferencia también de Chevalier, el libro de Gibson enfocó la historia rural a través de la etnohistoria, es decir, de la historia de los indios. En palabras de Lockhart, este libro "fue el primer escrito importante en el campo de la historia latinoamericana que enfocó a los indios como tema principal de estudio" ${ }^{22}$ Ciertamente existen antecedentes en obras como las de Lewis Hanke y, me atrevo afirmar, de Manuel Gamio en donde los indios pasan a un primer plano. Gibson consolidó estos antecedentes y supo articular una nueva visión de la historia latinoamericana, a través de nuevas fuentes y métodos. Por ejemplo, desarrolló también la perspectiva regional, en donde los actores son gentes comunes y locales, no los personajes heroicos de las historias tradicionales. Mostró además un elemento clave: la participación activa del indio en la definición de sus formas de gobierno, lo cual le permitió defender sus intereses corporativos.

El otro importante libro de Gibson que contribuyó en particular al debate sobre las haciendas y su relación con las comunidades indígenas fue el de Los aztecas bajo el dominio español, 1519-1810. ${ }^{23}$ Lo original en este libro de Gibson fue el presentar a las haciendas básicamente orientadas al mercado y con gran proporción de tra-

21. Apareció publicada por Yale University Press, 1952, 300 pp. Otra obra que encajó perfectamente con el modelo de Chevalier fue otro gran clásico: W. Borah, New Spain's Century of Depression, Berkeley, 1951. Puede hablarse de hecho de un gran paradigma Chevalier-Gibson-Borah, el cual continúa guiando las investigaciones sobre la historia rural del México colonial.

22. James Lockhart, "Charles Gibson y la etnohistoria del centro del México Colonial" en Historias 20, Abril-Septiembre de 1988, pp.25-47. La cita en la p. 26. 23. Traducción al español de Julieta Campos, Ed. Siglo XXI, 1967, 533 pp. 
bajadores temporales. Sin embargo, respecto a la relación con las comunidades indígenas destacó constantemente la pérdida de las tierras indígenas en manos de las haciendas, idea que reafirmó a final de cuentas el modelo de Chevalier. Por tal razón, a partir de estas obras de Gibson es que puede hablarse de un modelo más amplio, incluyendo incluso la obra de W. Borah sobre El siglo de la depresión, en donde se muestra cómo la caída de la población indígena propició nuevas formas de organización productiva y del trabajo que confluirían en la hacienda y el peonaje, formando de hecho un paradigma de la historia colonial. Paradigma que a partir de los años setentas comenzaría a ser claramente debatido.

\section{UNA VISION DESDE EL SUR: TAYLOR Y OSBORNE}

Veinte años después de publicada la obra de Chevalier apareció un libro directamente en discusión con el paradigma prevaleciente. ${ }^{24}$ Una visión etnohistórica desde el sur del México Colonial, el libro de Taylor mostró las diferencias regionales sobre el problema de la tierra de indios. En este sentido ejemplificó nuevamente las ventajas del análisis regional, en particular sobre las comunidades y sus tierras. Más que víctimas de la usurpación española, siguiendo en esto a su maestro Gibson, William B. Taylor demostró que dichas comunidades retuvieron suficiente tierra para subsistir y evitar la dependencia económica frente a los hacendados españoles, lo cual les otorgó el carácter de sujetos históricos activos.

Ante la pregunta sobre las causas de la retención de las tierras por parte de los indios, Taylor mencionó en un primer momento cuatro razones: a) la existencia de comunidades indígenas consolidadas al momento de la colonización, por lo cual pudieron defender de facto sus tierras a través por ejemplo de la composición; b) el sistema de justicia español que, pese a todo, otorgó a las comuni-

24. William B. Taylor, Landlord and Peasant in Colonial Oaxaca, Stanford, 1972. 
dades un instrumento legal de defensa; c) la persistencia y tenacidad de los indios para usar los recursos disponibles; d) la convicción de los españoles, civiles y funcionarios, de que los indios necesitaban tierras para cubrir sus tributos y abastecer el mercado. ${ }^{25}$

$\mathrm{Al}$ año siguiente, en 1973, apareció un artículo del historiador Wayne S. Osborn en el cual a través de un cuidadoso estudio sobre el actual Municipio de Metztitlán, Estado de Hidalgo, el autor amplía la crítica al paradigma Chevalier-Borah-Gibson. Lo interesante del caso es que no se trataba de una región alejada sino dentro del mismo Valle Central. Después de una detallada descripción de los patrones de tenencia de la tierra del siglo XVI al XviII, Osborn confirma el predominio de las tierras comunales sobre las españolas y agrega algunas razones más por las cuales los indios pudieron retener sus tierras: a) las condiciones geológicas del Valle de Metztitlán, las cuales propiciaban frecuentes inundaciones y, por consiguiente, el poco interés de los españoles sobre estas tierras; b) los pocos solicitantes españoles de tierras, especialmente en los siglos XVI y XVII, lo cual otorgó un periodo de gracia a las comunidades para que consolidaran sus tierras. ${ }^{26}$ Otras variables que menciona: la baja densidad de la población, sobre todo en los dos primeros siglos coloniales; el uso menos extensivo de la tierra, en fin, el papel de las autoridades indígenas. Por otra parte, de acuerdo con el mismo Osborn, cabe hacer notar que conforme la población india creció la tierra y la productividad fueron insuficientes. Esta pista, sin embargo, el autor no la desarrolla ampliamente, por lo cual extrañamos estudios que pongan en juego la dinámica de los recursos humanos y naturales.

En 1974, William Taylor publicó su visión desde el sur. Después de reseñar el problema que trajo consigo el que la hacienda se con-

25. Ibid., pp.107-110

26. Wayne S. Osborn, "Indian Land Retention in Colonial Metztitlán", Hispanic American Historical Review, Vol. 53:2, May 1973, pp. 217-238. 
virtiera en una abstracción y en un símbolo de la ideología del México revolucionario, el cual impidió ver otros factores que han influido en la pobreza rural, el autor analiza el surgimiento de los grandes latifundios en discusión con Chevalier y en relación a las comunidades indígenas. Según Taylor, Chevalier trabajó más para el Bajío y el norte, hasta Zacatecas, por lo cual su visión del sur "es básicamente legal (mercedes, composición) e institucional (Encomienda, Marquesado) y no considera en realidad el desarrollo de los sistemas de propiedad coloniales en el centro y en el sur". ${ }^{27}$

Así pues, los latifundios españoles existieron en Oaxaca pero no controlaban las mejores tierras de la región, ${ }^{28} \mathrm{ni}$ los indios dependían económicamente de las haciendas. Estas se establecieron de hecho en tierras vacantes, lo cual evitó muchos conflictos. Por otra parte, a diferencia con otras regiones, los cacicazgos indígenas fueron confirmados tempranamente más que desplazados.

Es interesante observar que el Profesor Taylor reconoce las razones proporcionadas por José Miranda años atrás para explicar el mismo fenómeno, tales como: el rechazo indígena a los valores individualistas; la distancia provocada por las leyes de segregación; el reconocimiento de la corona y de los conquistadores de las tierras de indios, y finalmente el poco número de españoles. Critica sin embargo a Miranda porque este subestimó la propiedad individual al interior de las comunidades, principalmente en manos de caciques. Aunque es necesario recordar que Miranda anticipó una explicación más, la permanencia de las autoridades indígenas, tema que discutiremos más adelante. Finalmente, Taylor ofrece una explicación del control de los españoles sobre los recursos, el cual provino fundamentalmente de los monopolios económicos-co-

27. William B. Taylor, "Landed Society in New Spain: A View from the South" Hispanic American Historical Review, Vol.54:3, August 1974, pp. 387-413. La cita en p. 396.

28. William B. Taylor, "Haciendas coloniales en el Valle de Oaxaca", Historia Mexicana, Vol. xxiII, Oct.-Dic., 1973. 
merciales más que de la tierra. En este sentido poco se ha estudiado el repartimiento de mercancías, clave para entender el sistema de explotación, en particular en Oaxaca.

En su introducción a la segunda edición en español de su obra clásica, Chevalier reseñó algunas de las aportaciones posteriores a la primera edición, a la vez que responde a algunos de sus críticos. Cito a Chevalier:

Las investigaciones confirman la diversidad de las situaciones, enseñándonos que en el valle de Oaxaca los indígenas habían logrado conservar la mayor parte de las tierras. Allí las haciendas eran pocas y cambiaban a menudo de propietario. No sorprenden estas conclusiones -continúa Chevalier- conociendo lo montañoso y áspero de la Mixteca y de los Zapotecas: ¡ni siquiera podían llegar a caballo a la villa de San Ildefonso, fundada por los españoles! (...) No nos sorprenderán tampoco que encuentren situaciones comparables a la de Oaxaca en zonas montañosas, de las muchas que hay en México y en América Central, e incluso en las tierras más ricas, por aisladas o más eficazmente protegidas por el viejo sistema español de la tutela, como ya lo hemos señalado (...) a reserva, sin embargo, de las investigaciones más precisas que necesitamos, no parece, en general, que las grandes llanuras mejor regadas y comunicadas del centro hayan seguido en posesión de comunidades. ${ }^{29}$

Gibson, por su parte, conociendo obviamente las críticas de sus alumnos, en un trabajo posterior concluyó afirmando que, en términos generales, las propiedades indígenas fueron constantemente amenazadas por los españoles, especialmente en periodos críticos, pese a las leyes protectoras y a otros argumentos. ${ }^{30}$

29. F. Chevalier, Op. cit., 2a. ed. en español, p. XV, Para un planteamineto diferente del propio Chevalier al preguntarse por los orígenes de las pequeñas propiedades en el centro-occidente de México, v. Heriberto Moreno García (Coord.), Después de los latifundios. La desintegración de la gran propiedad agraria en México, México, El Colegio de Michoacán-FONAPAS, 1982. Comentando la ponencia de Chevalier, Luis González resumió bien el problema: "El reparto de los baldíos no sólo produjo haciendas, también dio origen a muchos parvifundios.” (p. 10).

30. Charles Gibson, "Indian Societies under Spanish Rule" en Leslie Bethell ed. The Cambridge History of Latin America, Vol. 2, Cambridge, 1984, pp. 381-419. 
Por las respuestas anteriores, ¿qué podemos pensar de los trabajos críticos al paradigma Chevalier-Gibson? Estas críticas ¿representan acaso las excepciones que confirman la regla? A mi modo de ver, como espero haber dejado claro en esta larga reseña, es que la respuesta al problema de la retención de la tierra en manos indígenas muestra, por una parte la pluralidad geográfica y cultural del México rural; e historiográficamente, por otra parte, plantea nuevas preguntas a viejos problemas, algunos anticipados magistralmente como por ejemplo en los trabajos de José Miranda. ¿Quiere decir esto último que nos enfrentamos a un problema mal planteado? No, porque en la búsqueda de las diferencias (por cierto, claves según Marc Bloch en el método comparativo) se descubrieron nuevas fuentes y, especialmente en el caso de Taylor, nuevas metodologías. Sin embargo, la discusión sólo mostró variantes de un mismo modelo. El cuestionamiento de fondo al paradigma, como anticipé, proviene más que nada de las relaciones económicas de la hacienda y del sistema rural en general. Sin embargo, éste es otro problema, tema de una diferente revisión historiográfica.

\section{NUEVAS APORTACIONES Y REFLEXIONES FINALES}

Nancy M. Farris, a través de sus estudios sobre Yucatán, se planteó el mismo problema de la retención de las tierras indígenas y su respuesta fue diferente a la de Taylor:

En cuanto los españoles tuvieron el incentivo necesario para adueñarse de las tierras que los mayas querían retener -un incentivo que apareció tardíamente y que en algunos distritos no se dio- se apoderaron de ellas. Las comunidades con un liderazgo astuto y enérgico pudieron resistir temporalmente a través de litigios y diversos estratagemas planteados en el momento, pero no pudieron impedirlo. ${ }^{31}$

31. Nancy M. Farris, "Propiedades territoriales en Yucatán en la época colonial. Algunas observaciones acerca de la pobreza española y la autonomía indígena" en Historia Mexicana, Vol. Xxx: 2, Oct.-Dic. de 1980, pp.153-208. Itálicas de VMGE. 
Ronald Spores, trabajando sobre la misma región de Taylor, descubrió elementos claves que hacen más complejo el caso mixteco. En primer lugar, si bien los españoles no adquirieron o no se apoderaron de grandes extensiones de tierras, Spores descubrió que lo más común al respecto fue la renta, más que la venta de las tierras comunales. En segundo, un aspecto clave para esta región, la participación de la Iglesia. Dice Spores: "Si hubo un villano en la Mixteca Alta, lo fue la Iglesia con su casta de funcionarios". ${ }^{32}$ En otras palabras, quienes monopolizaron las tierras indígenas fueron los representantes religiosos, a través de las cofradías o hermandades, o bien a través de donaciones por herencia. Ello complica ciertamente la situación porque, a final de cuentas, ¿a quién beneficiaba la retención de las tierras indígenas?

Siguiendo en el sur, Judith Francis Zeitlin escribió un brillante artículo que profundiza sobre las causas de la sobrevivencia de las tierras de indios en tres comunidades del Istmo de Tehuantepec. El ensayo consistió en observar tres comunidades sujetas a similares presiones externas, Tehuantepec fue una zona intensamente explotada desde la colonia, pero con diferente lengua y distinta organización política interna. El resultado fue esclarecedor. Para la autora, una élite hereditaria, con responsabilidades ancestrales como las de organizar las actividades de la comunidad, así como la de jugar el papel de mediador entre el mundo español y el mundo indígena, "jugó un papel clave al mantener los límites sociales y económicos frente a la intensa presión española sobre la tierra" ${ }^{33}$

William B. Taylor había escrito en 1970 precisamente sobre el papel clave de los cacicazgos en Oaxaca. ${ }^{34}$ Sin embargo, en su com-

32. Ronald Spores, The Mixtecs in Ancient and Colonial Times, University of Oklahoma Press, Norman, 1984, en especial pp. 130-134.

33. Judith Francis Zeitlin, "Rancher and Indians on the Southern Isthmus of Tehuantepec: Economic Change and Indigenous Survival Colonial Mexico", Hispanic American Historical Review, Vol. 69:1, 1989, pp. 23-59.

34. William B. Taylor, "Cacicazgos coloniales en el Valle de Oaxaca", Historia Mexicana, Vol. 20:1, 1970. 
paración con el Valle Central, se inclinó por la explicación del diferente grado de presión española, es decir, más por una causa externa que interna. Aunque no puede esgrimirse una sola causa para explicar un fenómeno complejo, quizá el argumento más convincente tenga que ver con la permanencia o no de la nobleza indígena y las formas de gobierno.

Sobre esto último cabe mencionar, entre una gran literatura que sería tema de otro trabajo, el reciente artículo de Robert Haskett, ${ }^{35}$ quien analizando el cabildo colonial en Cuernavaca, Morelos, mostró formas de gobierno sofisticadas, con un desarrollado sistema judicial y de administración de la tierra colonial, capaz de promulgar frecuentes reglamentos. Finalmente, habría que considerar el trabajo de Bernardo García ya aludido en la introducción, cuya distinción entre propiedad y jurisdicción en las tierras de indios abre una perspectiva de investigación fructífera, ya que la jurisdicción de las comunidades prehispánicas no necesariamente incluía una base territorial sino de asociación política. De hecho, para el autor la frecuente confusión entre ambas esferas, como en el caso de la encomienda dentro del mundo español, llevó por un lado a la pérdida de las antiguas formas prehispánicas; sin embargo, habría que decir, de acuerdo a lo argumentado en este trabajo, que en donde el concepto de jurisdicción (es decir de asociación política a través de los cacicazgos) logró resistir, la retención de las tierras por parte de las comunidades indígenas fue más efectiva.

Existe una línea de interpretación que me gustaría destacar como reflexión final. Así como Marc Bloch interpretó la historia rural francesa a partir de lo que tituló como "el esfuerzo por el individualismo agrario", ${ }^{36}$ el enfrentamiento entre los bienes comunales y los cercados, en cierta forma puede observarse en Chevalier

35. "Indian Town Government in Colonial Cuemavaca: Persistence, Adaptation and Change", Hispanic American Historical Review, Vol. 67:2, May 1987, pp. 203-231.

36. Marc Bloch, La historia rural francesa, Barcelona, Ed. Crítica-Grijalbo, 1966. 
el mismo enfoque al resumir la historia rural mexicana enfrentando a la hacienda con las comunidades. Sin embargo, bajo esta misma perspectiva pareciera que Chevalier simplificó el problema. Esto es, la tendencia global en el mundo moderno hacia el individualismo de los bienes comunales no se ha realizado en México sólo a través de la apropiación efectuada por las haciendas españolas. Las mismas comunidades indígenas, por el crecimiento natural de la población y la disponibilidad de un recurso escaso como la tierra y el agua, tendieron, sobre todo a partir de la segunda mitad del siglo XVIII a privatizar sus tierras, lo cual ciertamente implicó el fin del viejo concepto jurisdiccional y de asociación política vinculado a la propiedad.

Hace falta profundizar más en este proceso, aunque existen ya algunos estudios que lo han considerado, como el de Nancy Farris ya citado, o el de Margarita Loera, quien a través de un análisis de testamentaría indígena demostró esta tendencia a privatizar en Calimaya, Estado de México ${ }^{37} 0$ el de Rodolfo Pastor, quien en un breve pero esclarecedor apartado escribió sobre "la privatización de la economía indígena" en la Mixteca, al menos desde el siglo XVII pero con mayor intensidad en el siglo XVIII. ${ }^{38}$ Ahora bien, esta tendencia hacia la privatización ocurrió no sólo por la ambición de los españoles, ni por las políticas fisiocráticas de la corona. Es un cambio que tiene que ver con los ritmos de los procesos "individualizadores" (o de las contradicciones del desarrollo capitalista, en otro términos) en el México colonial frente a las transformaciones de la economía mundial.

Mucho se ha especulado sobre las consecuencias de estos cambios, sin embargo, aún no conocemos suficientemente las desamor-

37. Margarita Loera, "La herencia indígena como mecanismo de reproducción campesina: Calimaya en la época colonial”, Historias, Abril-Dic. de 1983, pp. 11-26. 38. Rodolfo Pastor, Campesinos y reformas: La mixteca, 1700-1856, El Colegio de México, 1987. 
tizaciones o impulsos privatizadores, dado que el fenómeno aparece frecuentemente como negativo debido el efecto concentrador y no redistributivo que ha tenido en nuestra historia. No obstante, me pregunto si las políticas borbónicas o las leyes de reforma efectivamente afectaron a las comunidades o bien las liberararon de una carga en un proceso complejo de cambio sociocultural. Ahora bien, se ha planteado en varias ocasiones que la pérdida de la propiedad indígena es la pérdida del indio y, por lo tanto, de un mundo que cuestiona con su presencia la modernización a ultranza. Sin embargo, la identidad indígena proviene no sólo de la tierra sino de la subordinación a un principio jerárquico. La pregunta en todo caso tendría que dirigirse hacia las formas de gobierno "patrimoniales," por usar un concepto weberiano, en donde la distinción entre lo público y lo privado no es muy marcada.

Una perspectiva que también requiere más desarrollo es atendiendo al consumo de mercancías. Esta nos vincula no sólo con esa forma de explotación sobre las comunidades indígenas que fue el repartimiento de mercancías, sino también con las presiones del mercado sobre las mismas comunidades y el mundo rural mexicano. Habría que incluir la evolución del consumo tanto regional como internacional, en particular el ganadero, tal y como lo ha sugerido B. H. Slicher Van Bath para la historia agraria de Europa Occidental. ${ }^{39}$ A final de cuentas, podríamos concluir, que no obstante las críticas muchas veces apresuradas al paradigma Chevalier-Borah-Gibson, éste sigue solicitando, sigue planteando preguntas.

39. B. H. Slicher Van Bath, Historia Agraria de Europa Occidental, 500-1850, Barcelona, Ed. Península, 1974, 503 pp. William H. Dusenberry, The Mexican Mesta. The administration of ranching in Colonial Mexico. University of Illinois Press, 1963. Uno de los primeros estudios sobre la institución de la ganadería trashumante en México. 